\title{
Mind-Body Medicine in the Secondary Prevention of Coronary Heart Disease
}

\author{
A Systematic Review and Meta-analysis
}

Holger Cramer, Romy Lauche, Anna Paul, Jost Langhorst, Andreas Michalsen, Gustav Dobos

\section{SUMMARY}

Background: In mind-body medicine (MBM), conventional lifestyle modification measures such as dietary counseling and exercise are supplemented with relaxation techniques and psychological motivational elements. This review studied the effect of MBM on cardiac events and mortality in patients with coronary heart disease (CHD).

Methods: This review is based on publications up to and including January 2015 that were retrieved by a systematic search in PubMed, the Cochrane Library, and Scopus. Randomized controlled trials of the effect of MBM programs (versus standard treatment) on cardiac events, overall mortality, and/ or cardiac mortality were analyzed. Atherosclerosis, blood pressure, LDL cholesterol, and the body mass index (BMI) were chosen as secondary outcomes. Random-effects meta-analyses were performed. The risk of bias was assessed with the Cochrane tool.

Results: Twelve trials, performed on a total of 1085 patients, were included in the analysis. Significant differences between groups were found with respect to cardiac events (odds ratio [OR]: $0.38 ; 95 \%$ confidence interval [CI]: $0.23-0.61 ; p<0.01$; heterogeneity $\left[I^{2}\right]: 0 \%$ ), but not overall mortality (0R: 0.82 ; $95 \%$ Cl: $0.46-1.45 ; p=0.49 ; I^{2}: 0 \%$ ) or cardiac mortality (0R: $0.98 ; 95 \% \mathrm{Cl}$ : $\left.0.43-2.25 ; p=0.97 ; l^{2}: 0 \%\right)$. Significant differences between groups were also found with respect to atherosclerosis (mean difference $[\mathrm{MD}]=-7.86 \%$ diameter stenosis; 95\% Cl: $\left.-15.06-[-0.65]^{\prime} p=0.03 ; l^{2}: 0 \%\right)$ and systolic blood pressure (MD = $\left.-3.33 \mathrm{~mm} \mathrm{Hg} ; 95 \% \mathrm{Cl}:-5.76-[-0.91] ; \mathrm{p}<0.01 ; \mathrm{I}^{2}: 0 \%\right)$, but not with respect to diastolic blood pressure, LDL cholesterol, or BMI.

Conclusion: In patients with CHD, MBM programs can lessen the occurrence of cardiac events, reduce atherosclerosis, and lower systolic blood pressure, but they do not reduce mortality. They can be used as a complement to conventional rehabilitation programs.

\section{- Cite this as:}

Cramer H, Lauche R, Paul A, Langhorst J, Michalsen A, Dobos G: Mind-body medicine in the secondary prevention of coronary heart disease-a systematic review and meta-analysis. Dtsch Arztebl Int 2015; 112: 759-67.

DOI: 10.3238/arztebl.2015.0759

Department of Internal and Integrative Medicine, Kliniken Essen-Mitte, Faculty of Medicine, University of Duisburg-Essen, Essen: Dr. Cramer, Dr. Lauche, Dr. Paul, Prof. Langhorst, Prof. Dobos

Department of Internal and Complementary Medicine, Immanuel Hospital, Berlin: Prof. Michalsen

Institute for Social Medicine, Epidemiology, and Health Economics, Charité-Universitätsmedizin, Berlin: Prof. Michalsen oronary heart disease (CHD) is one of the most widespread diseases. It has a lifetime prevalence of $9.3 \%$ in 40 - to 79 -year-olds (1) and is the most common cause of death in Germany (2). According to data from the World Health Organization (WHO), around $80 \%$ of the risk factors for CHD can be influenced by the patient's behavior; this applies above all to lack of exercise, poor nutrition, overweight, and chronic subjective stress $(3,4)$. Correspondingly, the German National Disease Management Guideline on chronic CHD recommends secondary prevention as an integral component of the comprehensive long-term care of patients with cardiac disease (5). The preventive measures should cover the areas of nutrition, exercise/sport, and stress reduction/relaxation.

Particularly in the USA, intensive mind-body medicine (MBM) programs for lifestyle modification have been developed that integrate these components into standardized secondary preventive interventions (6). MBM focuses on achieving self-regulation by means of preventive and curative interactions between the brain, the rest of the body, the mind, and behavior (6-9).

In contrast to many other programs for lifestyle modification, MBM interventions include not only nutritional advice and exercise/sport, but also relaxation techniques and psychological motivational elements $(6$, 7,9).

While the effects of single components or interventions (10-12) and of less intensive lifestyle modification programs (13-15) have been repeatedly studied, no meta-analyses of the effectiveness of complex MBM interventions have yet been published. The aim of this review was to perform a systematic analysis of the evidence from randomized trials on the effect of MBM interventions on cardiac events and mortality in comparison with standard treatment in patients with CHD.

\section{Methods}

This review was conducted and reported in accordance with the PRISMA guidelines (16) and the recommendations of the Cochrane Collaboration (17). The protocol was drawn up a priori and not changed in any way during the course of the review; it was not published in advance. 


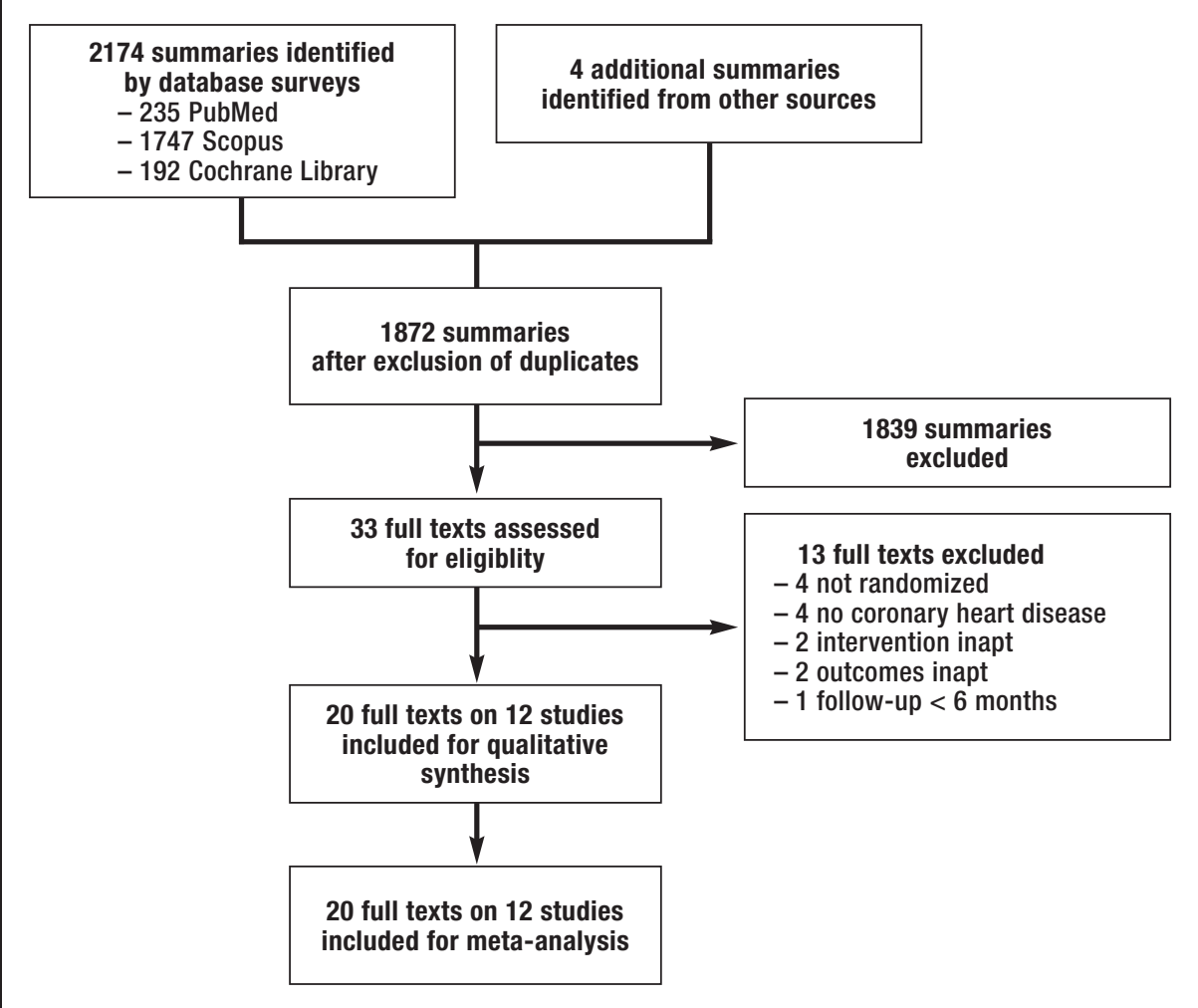

\section{Inclusion criteria}

Studies fulfilling the following criteria were included in the review:

Study type-Only randomized controlled trials were included. The language of publication was not a criterion.

Participants - Studies on adult patients ( $\geq 18$ years) with diagnosed CHD were included.

Experimental interventions - Trials of MBM interventions were included. These interventions had to include theoretical and practical training in at least the following three components:

- Nutrition

- Exercise/sport

- Stress reduction/relaxation.

Studies in which pharmacological treatments formed part of the intervention but the controls did not receive the same pharmacotherapy were excluded.

Control interventions-Trials that compared the experimental intervention with a standard treatment (pharmacological, lifestyle, or multimodal interventions) were included. However, studies in which the control intervention corresponded to the above definition of the experimental intervention were excluded.

Outcomes-Trials were included that acquired data on at least one of the following primary outcomes-with follow-up for $\geq 6$ months after randomization:
- Cardiac events (number of patients with acute myocardial infarction, coronary artery bypass, and/or coronary angioplasty)

- Overall mortality

- Cardiac mortality.

The following were defined as secondary outcomes:

- Atherosclerosis

- Systolic and diastolic blood pressure

- LDL cholesterol

- Body mass index (BMI).

\section{Search strategy}

The systematic search strategy included both electronic databases and manual screening of reference lists. The databases PubMed, Cochrane Library, and Scopus were searched for relevant articles published in or before January 2015 (eTable 1). All identified summaries were read independently by two reviewers (HC and RL) and assessed as to their suitability. Potentially suitable publications were read in full. In the event of disagreement, a third reviewer (GD) was consulted and a consensus reached.

\section{Data extraction}

Data on patients, interventions, outcomes, and results were extracted independently by two reviewers (HC and RL) with the aid of an a priori designed data extraction sheet. In the event of disagreement, a third reviewer (GD) was consulted and a consensus reached. 


\section{Determination of risk of bias in individual studies}

Two reviewers (HC and RL) independently used the Cochrane Collaboration instrument (17) to assess the risk of bias as "low," "high," or "unclear" in the following areas:

- Selection (random sequence generation, allocation concealment)

- Performance (blinding of participants and personnel)

- Detection (blinding of outcome assessment)

- Attrition (incomplete outcome data)

- Report (selective reporting)

- Other.

In the event of disagreement, a third reviewer (GD) was consulted and a consensus reached.

\section{Data analysis}

The categorical primary outcomes were evaluated using the generic inverse variance method based on random effects models. Log odds ratios and the associated standard errors were calculated in a standardized Excel spreadsheet (in trials with empty cells, 0.5 was added to all cells [18]). On the basis of these data, Review Manager 5 (version 5.2, The Nordic Cochrane Centre, Copenhagen, Denmark) was used to establish the odds ratio (OR) and 95\% confidence intervals (95\% CI) (17). In the case of significant differences between groups we calculated the number needed to treat (NNT) with $95 \%$ CI.

Secondary outcomes were evaluated as continuous variables with the aid of mean differences (MD) and standardized mean differences (SMD) (17). Missing standard deviations were either calculated from the standard error, CI, or t-values (17) or imputed as the mean standard deviation of the remaining trials.

The data for the primary outcomes were extracted from the latest follow-up findings, the data for the secondary outcomes at the earliest time point after the end of the intervention.

Statistical heterogeneity was determined on the basis of $\mathrm{I}^{2}$. The heterogeneity was classified as low if $\mathrm{I}^{2}$ was between $0 \%$ and $24 \%$, moderate between $25 \%$ and $49 \%$, substantial between $50 \%$ and $74 \%$, and high between $75 \%$ and $100 \%(17,19)$. The significance of heterogeneity was verified using the chisquare test. Owing to the low power of this test, $p$ $\leq 0.10$ was defined as indicating a significant difference (17).

\section{Subgroup and sensitivity analyses}

Sensitivity analyses were carried out to test the robustness of significant results. These analyses only included either studies with low risk of selection bias (i.e., adequate random sequence generation and allocation concealment) or studies with low risk of detection bias (i.e., adequate blinding of outcome assessment).

\section{Publication bias}

The risk of publication bias was assessed by visual inspection of funnel plots produced using Review
Manager, provided the corresponding meta-analysis included at least 10 trials $(17,20)$. Relatively symmetrical funnel plots indicated low risk of bias, while asymmetric plots indicated high risk of bias.

\section{Results}

\section{Literature survey}

The literature search threw up 1872 non-duplicated results. Of these, 1839 were excluded because their title and summary showed that they did not meet the inclusion criteria (Figure 1). The remaining 33 publications were read in full. Thirteen of these were excluded for the following reasons:

- The studies were not randomized (e1-e4)

- Not all patients had a diagnosis of CHD (e5-e8)

- The intervention did not include stress reduction/ relaxation $(\mathrm{e} 9, \mathrm{e} 10)$

- None of the primary outcomes was acquired (e11, e12)

- The duration of follow-up was less than 6 months (e13).

The 20 full-text articles (21-40) that were eventually included reported the results of 12 randomized trials with a total of 1085 patients.

\section{Study characteristics}

The Table and the supplementary eTable 2 show the characteristics of the 12 trials that were included. Two of them were carried out in Germany $(21,30)$, three in Sweden $(24,25,27,28,35,36)$, three in the USA $(20$, 21, 32, 33, 38, 39), and one each in Portugal (31), Norway (40), Thailand (37), and India (29).

The sample size ranged from 28 to 224 with a median of 79 patients. Between 0 and $100 \%$ of the patients (median 81.1\%) were men; the average age ranged from 51.9 to 66.0 years (median 59.6 years). The duration of the intervention varied widely. The shortest intervention was 4 days, followed by 12 months of putting into practice what had been learned (29). The longest intervention comprised 24 months of supervised treatment (40). In most studies the duration of the supervised intervention was 12 months (21-23, 30, 32, 33, 35, 37-39). All 12 trials recorded overall mortality, at times varying from 6 months to 19 years (median 2 years) after the intervention; 10 trials reported cardiac mortality, between 6 months and 7 years (median 2 years); and six trials registered cardiac events after 1 to 7 years (median 2.5 years). Atherosclerosis was measured after 1 to 7 years, blood pressure after 6 months to 2 years, LDL cholesterol after 6 months to 2 years, and BMI after 6 months to 2 years (median 1 year in each case).

\section{Risks of bias in individual studies}

The risk of bias is shown in eTable 3. Three trials presented a low risk of selection bias $(24,30,35,36)$, while four trials reported adequate blinding of outcome assessment (21, $23,30,32,33,35,37)$.

\section{Data analysis}

The results of qualitative and quantitative data analysis were as follows: 


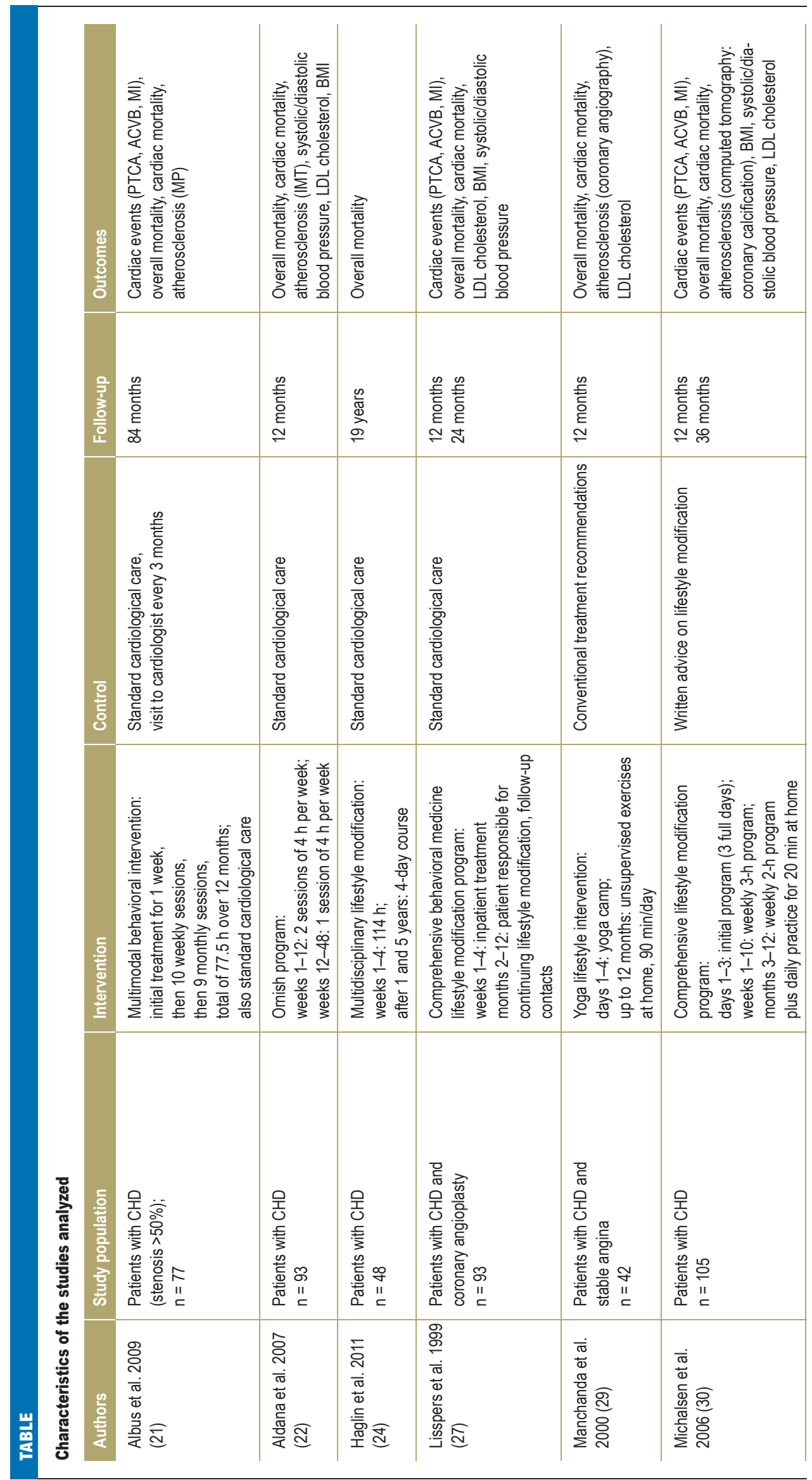




\begin{tabular}{|c|c|c|c|c|c|c|}
\hline 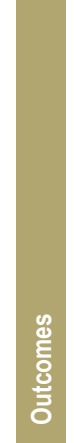 & 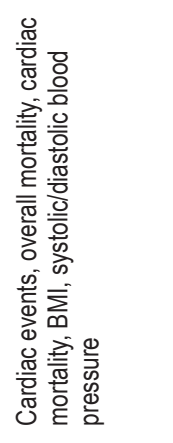 & 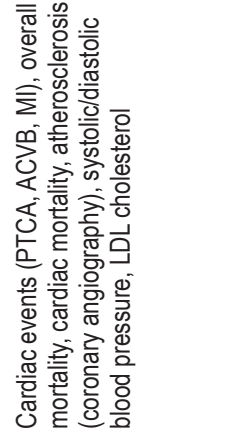 & 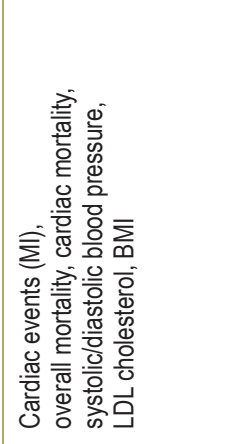 & 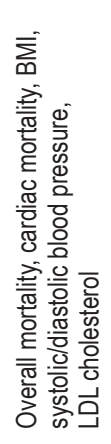 & 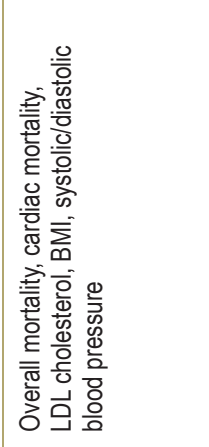 & 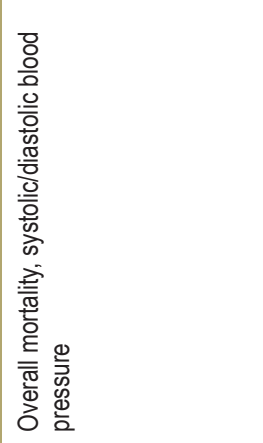 \\
\hline $\begin{array}{l}\text { 을 } \\
\text { 흥 } \\
\text { 훈 }\end{array}$ & 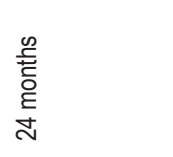 & 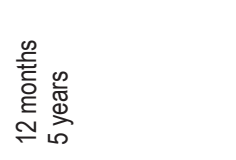 & 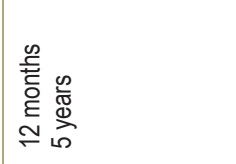 & 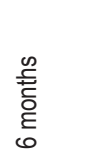 & 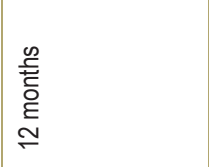 & 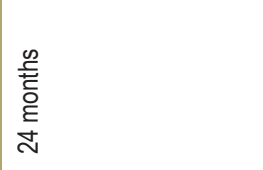 \\
\hline & 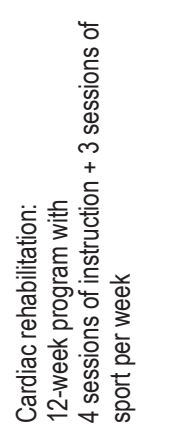 & 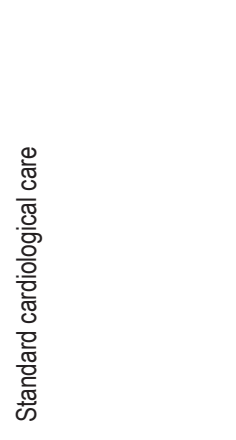 & 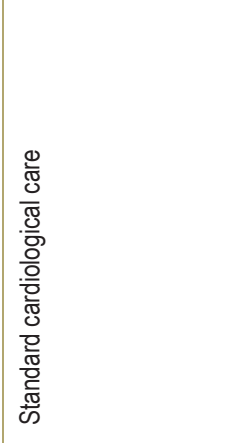 & 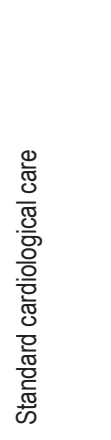 & 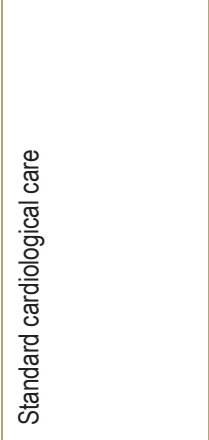 & 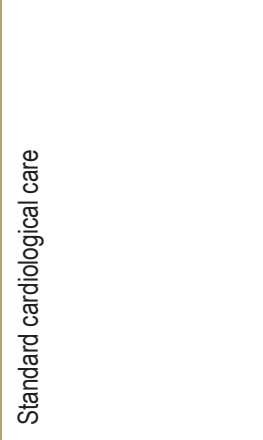 \\
\hline 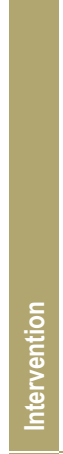 & 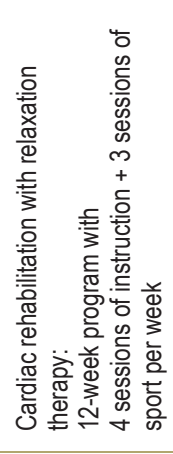 & 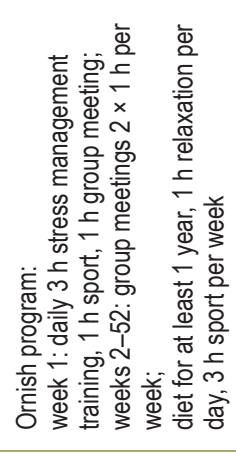 & 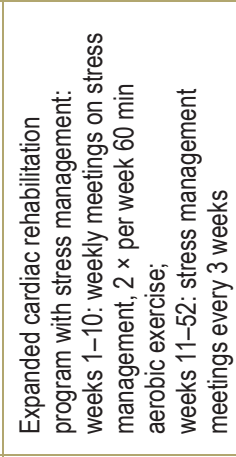 & 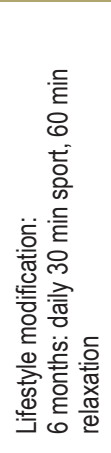 & 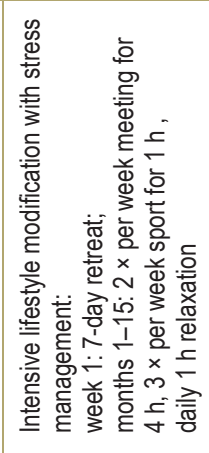 & 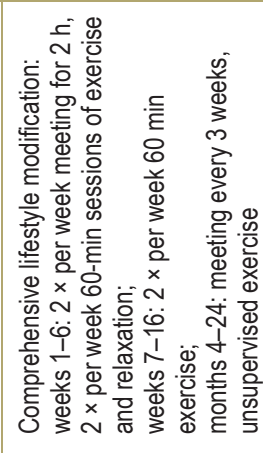 \\
\hline & 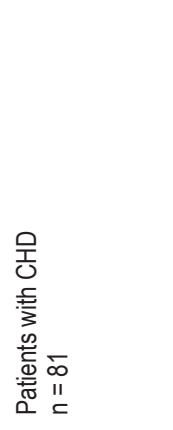 & 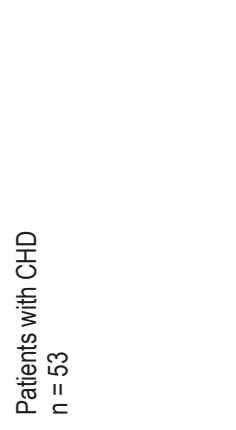 & 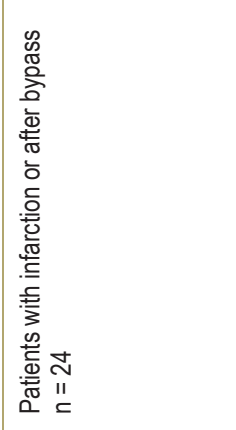 & 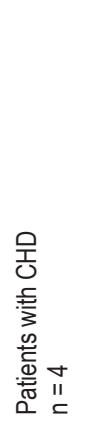 & 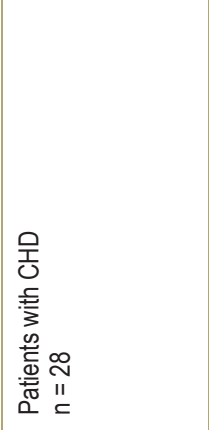 & 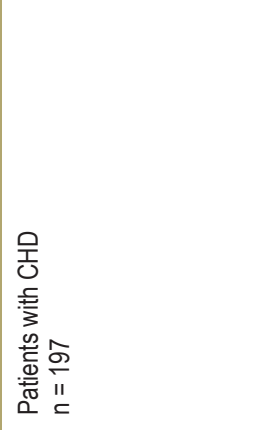 \\
\hline 素 & 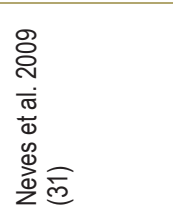 & 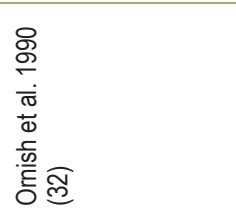 & 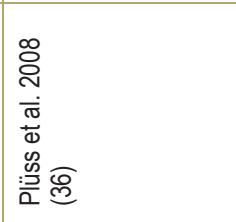 & 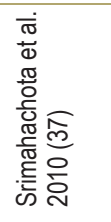 & 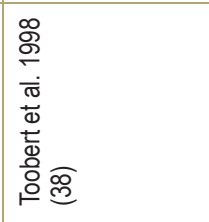 & 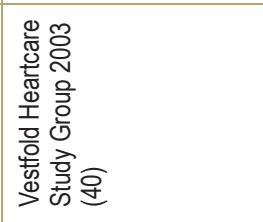 \\
\hline
\end{tabular}




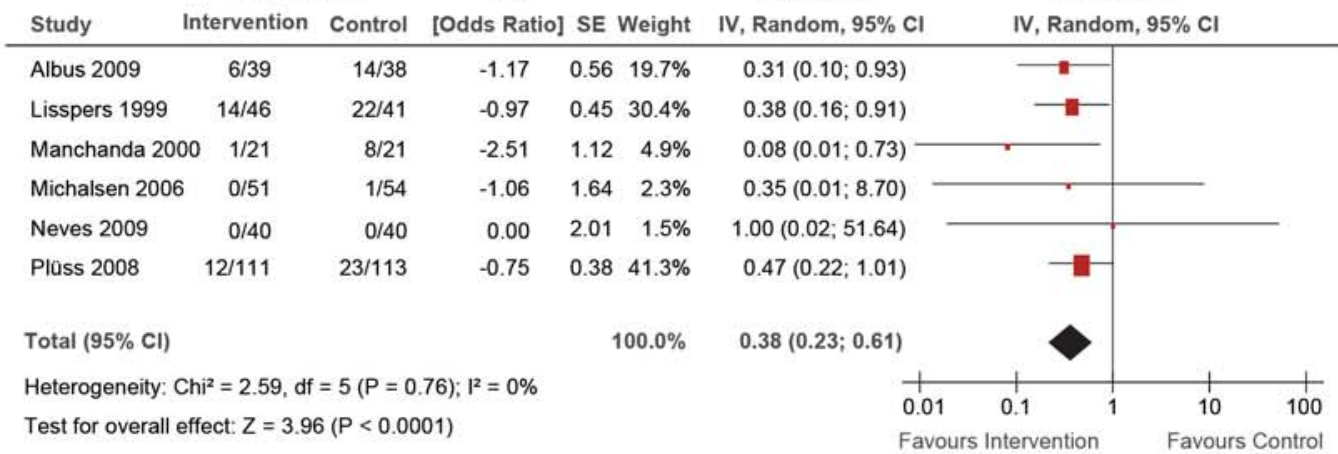

\begin{tabular}{|c|c|c|c|c|c|c|c|c|}
\hline \multirow{2}{*}{$\begin{array}{l}\text { Study } \\
\text { Albus } 2009\end{array}$} & \multicolumn{2}{|c|}{ Events/Total } & $\log$ & I SE & Weight & $\begin{array}{c}\text { Odds Ratio } \\
\text { IV, Random, } 95 \% \mathrm{CI}\end{array}$ & \multicolumn{2}{|c|}{$\begin{array}{c}\text { Odds Ratio } \\
\text { IV, Random, } 95 \% \mathrm{Cl}\end{array}$} \\
\hline & $2 / 39$ & $3 / 38$ & -0.46 & 0.94 & $9.8 \%$ & $0.63(0.10 ; 4.00)$ & $\longrightarrow$ & \\
\hline Aldana 2007 & $0 / 46$ & $2 / 47$ & -1.63 & 1.56 & $3, \%$ & $0.20(0.01 ; 4.19)$ & & \\
\hline Haglin 2011 & $15 / 36$ & $6 / 12$ & -0.34 & 0.67 & $19.5 \%$ & $0.71(0.19 ; 2.65)$ & $\rightarrow$ & \\
\hline Lisspers 1999 & $1 / 46$ & $6 / 41$ & -2.04 & 1.10 & $7.2 \%$ & $0.13(0.01 ; 1.13)$ & & \\
\hline Manchanda 2000 & $0 / 21$ & $0 / 21$ & 0.00 & 2.02 & $2.1 \%$ & $1.00(0.02 ; 52.79)$ & & \\
\hline Michalsen 2006 & $0 / 51$ & $3 / 54$ & -1.95 & 1.52 & $3.7 \%$ & $0.14(0.01 ; 2.84)$ & & \\
\hline Neves 2009 & $0 / 40$ & $0 / 40$ & 0.00 & 2.01 & $2.2 \%$ & $1.00(0.02 ; 51.64)$ & & \\
\hline Ornish 1990 & $2 / 28$ & $1 / 20$ & 0.38 & 1.26 & $5.5 \%$ & $1.46(0.12 ; 1732)$ & & \\
\hline Plūss 2008 & $10 / 111$ & $8 / 113$ & 0.26 & 0.49 & $35.6 \%$ & $1.30(0.49 ; 3.42)$ & & \\
\hline Srimahachota 2010 & $0 / 15$ & $0 / 15$ & 0.00 & 2.03 & $2.1 \%$ & $1.00(0.02 ; 53.77)$ & & \\
\hline Toobert 1998 & $1 / 14$ & $0 / 11$ & 0.93 & 1.68 & $3.1 \%$ & $2.54(0.09 ; 68.81)$ & & \\
\hline Vestfold 2003 & $2 / 98$ & $1 / 99$ & 0.71 & 1.23 & $5.7 \%$ & $2.04(0.18 ; 22.89)$ & & \\
\hline Total $(95 \% \mathrm{Cl})$ & & & & & $100.0 \%$ & $0.82(0.46 ; 1.45)$ & & \\
\hline \multicolumn{7}{|c|}{ Heterogeneity: $\mathrm{Chi}^{2}=7.17, \mathrm{df}=11(\mathrm{P}=0.78) ; \mathrm{I}^{2}=0 \%$} & & \\
\hline \multicolumn{7}{|c|}{ Test for overall effect: $Z=0.69(P=0.49)$} & $\begin{array}{c}0.1 \quad 1 \\
\text { Intervention }\end{array}$ & $\begin{array}{c}10 \\
\text { Favour: }\end{array}$ \\
\hline
\end{tabular}

B Test for overall effect: $Z=0.69(P=0.49)$

Events/Total $\quad \log \quad$ Odds Ratio Odds Ratio

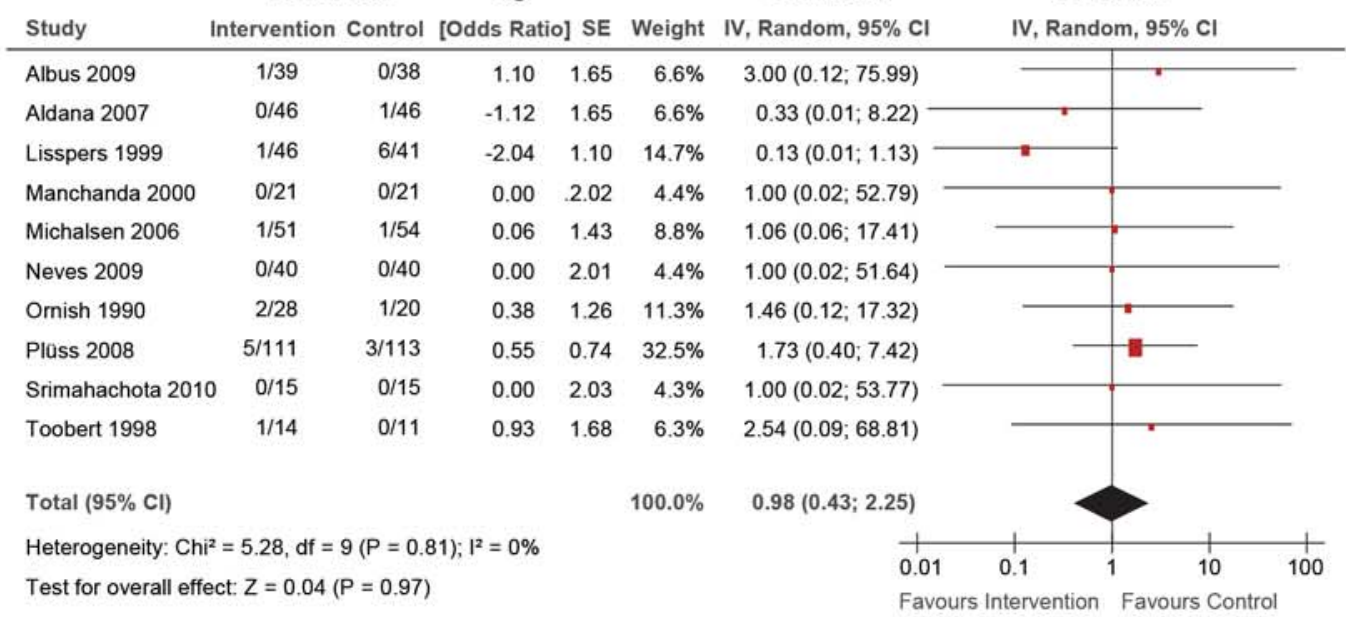

Meta-analyses of primary outcomes:

A) cardiac events; B) overall mortality; C) cardiac mortality.

IV, inverse variance; $\mathrm{Cl}$, confidence interval, $\mathrm{SE}$, standard error 
Primary outcomes-There was a significant group difference in the incidence of cardiac events, which occurred in 33 of 308 patients in the intervention groups and 68 of 307 patients in the control groups (OR 0.38, $95 \%$ CI $0.23-0.61 ; \mathrm{p}<0.01 ;$ Figure 2$)$. The heterogeneity was low $\left(\mathrm{I}^{2} 0 \% ; \mathrm{p}=0.76\right)$, and the NNT was $8.33(95 \%$ CI 4.17-100.00). No significant differences were found between the groups for overall mortality or cardiac mortality (Figure 2). Altogether, 33 of 545 patients in the intervention groups and 30 of 511 patients in the control groups died (OR 0.82, 95\% CI 0.46-1.45; p =0.49). Eleven of 411 patients in the intervention groups and 12 of 399 patients in the control groups died of cardiac causes (OR 0.98, 95\% CI 0.43-2.25; $\mathrm{p}=0.97$ ).

Secondary outcomes-The meta-analysis revealed a significant group difference for atherosclerosis $(\mathrm{MD}=-7.86 \%$ diameter stenosis; 95\% CI $-15.06-[-0.65]$; $\mathrm{p}=0.03$; eFigure 1$)$; the heterogeneity was low $\left(\mathrm{I}^{2} 0 \%\right.$; $\mathrm{p}=0.91)$. However, two studies whose data could not be included in the meta-analysis reported no difference between the groups for atherosclerosis $(22,39)$. Another study found a significant difference in the occurrence of myocardial perfusion as an indirect measure of atherosclerosis (21). When this study was included in the meta-analysis, the difference between the groups remained significant $(\mathrm{n}=146$; SMD $-0.55,95 \%$ CI $\left.-0.99-[-0.22] ; \mathrm{p}<0.01 ; \mathrm{I}^{2} 0 \%\right)$. A group difference was also found for systolic blood pressure $(\mathrm{MD}=$ $\left.-3.33 \mathrm{~mm} \mathrm{Hg}, 95 \% \mathrm{CI}-5.76-[-0.91] ; \mathrm{p}<0.01 ; \mathrm{I}^{2} 0 \%\right)$, but not for diastolic blood pressure, LDL cholesterol, or BMI (eFigure 1).

\section{Sensitivity analyses}

If only trials with a low risk of selection bias were included, only the group difference for cardiac events remained significant (OR 0.47 , 95\% CI 0.22-0.97; $\left.\mathrm{p}=0.04 ; \mathrm{I}^{2} 0 \%\right)$. In the two studies concerned $(30,35$, 36), cardiac events occurred in 12 of 162 patients in the intervention groups and 24 of 167 patients in the control groups. When only trials with a low risk of detection bias $(21,23,30,32,35-37)$ were included, there were significant differences between the groups for cardiac events (OR 0.41, 95\% CI 0.22-0.76; $<<0.01 ; \mathrm{I}^{2} 0 \%$ ) and atherosclerosis (SMD $-0.58,95 \%$ CI $-0.98-[-0.19]$; $\left.\mathrm{p}<0.01 ; \mathrm{I}^{2} 0 \%\right)$.

\section{Publication bias}

The funnel plots for overall mortality and cardiac mortality were relatively symmetrical (eFigure 2, eFigure 3), indicating a low risk of bias.

\section{Discussion}

This meta-analysis of 12 randomized trials with a total of 1085 CHD patients found significant effects on cardiac events, atherosclerosis, and systolic blood pressure after MBM interventions or intensive lifestyle modification compared to standard treatment. The decreased risk of cardiac events was robust against potential methodological bias. Heterogeneity was low, as was the risk of publication bias.

\section{Agreement with previous reviews}

To the best of our knowledge this is the first systematic review of the effect of mind-body medicine in coronary heart disease. However, less intensive modifications of lifestyle have been reviewed. De Waure et al. (13) evaluated a total of 14 randomized trials of behavioral interventions that included at least two of the following components: nutritional recommendations, psychological interventions, exercise/sport, and giving up smoking. There was some overlap between De Waure et al. and our review, but the trials included were largely different. The control interventions and the assessment of blinding were comparable. In contrast to our meta-analysis, that by De Waure et al. showed an effect on cardiac mortality but not on non-fatal cardiac events.

Another meta-analysis by Janssen et al. (14), including 23 randomized trials of lifestyle interventions showed group differences for overall mortality, cardiac mortality, and non-fatal cardiac events; however, these differences were all smaller than that found for cardiac events in our meta-analysis.

Again, the differences between the reviews are probably attributable mainly to the differences in inclusion criteria. Janssen et al. included all studies that focused on lifestyle factors. Moreover, the interventions ranged all the way from just advice on sports and nutrition to intensive lifestyle modification programs - all of which were also included in our review (22-24, 32, 33, 40) — and no restrictions were imposed regarding the control interventions used. The review by Janssen et al. (14) did not include evaluation of blinding. Although the power of the present metaanalysis is reduced by the smaller number of studies included, the greater homogeneity of interventions employed permits more accurate assessment of the practical utility of the findings.

Finally, a third previous review found, in agreement with our results, a reduction in atherosclerosis after lifestyle modification interventions comprising nutritional and/or sports programs (15).

\section{External and internal validity}

This meta-analysis includes trials carried out in Europe, North America, and Asia. In line with the epidemiology of CHD most of the patients were older males, although one trial explicitly included only women $(38,39)$. Therefore, the findings can be assumed to apply to patients encountered in clinical practice.

The risk of bias overall is rather high. Three and four of the studies were found to have a low risk of selection and detection bias respectively. While the risk of publication bias was low and the effects of the interventions on cardiac events were robust against bias and had low heterogeneity, the effects on the secondary outcomes were not verifiable in studies with low risk of selection bias. Internal validity thus seems to be present only for the effects of the interventions on cardiac events. 


\section{Strengths and limitations}

The strengths of this meta-analysis are the following:

- The comprehensive survey of the literature

- The clearly defined inclusion criteria, particularly with regard to the target interventions

- The assessment of the applicability of the findings in clinical practice (e14).

The greatest weakness is the restricted internal validity of the results. Moreover, the findings regarding atherosclerosis are limited by the low number of studies and the contradictory results depending on the method of investigation. The substantial differences in duration of follow-up could limit the power of the results particularly for the primary outcomes. Furthermore, it is uncertain whether the interventions in the individual trials are sufficiently homogeneous for the purposes of a meta-analysis. However, the low statistical heterogeneity in all analyses of primary outcomes speaks against systematic distortion of the results by the differences in intervention design or length of follow-up.

\section{Implications for future research}

Further studies are required to clarify the effect of intensified lifestyle modification on cardiovascular risk factors, particularly atherosclerosis and blood pressure. These studies should be conducted and reported in line with the widely accepted guidelines for clinical trials; only in this way can it be excluded that positive findings are the result of systematic distortion due to inadequate methods. Furthermore, it would be desirable to investigate the optimal intensity and duration of the intervention programs, as well as establishing which of the many existing exercise, nutrition, and relaxation programs are best for use in the secondary prevention of CHD.

\section{Implications for clinical practice}

The primary aim of secondary prevention and treatment of CHD is to exert a favorable influence on the course and prognosis of the disease. Owing to the reduction in the risk of cardiological events, MBM programs can be viewed as successful in affecting the disease course. Although there were no direct signs of reduction in mortality, non-fatal cardiac events have been proved to be an important

\section{KEY MESSAGES}

- Mind-body medicine (MBM) has developed intensified lifestyle modification programs for secondary prevention of coronary heart disease (CHD). These interventions cover the areas of nutrition, exercise, and relaxation.

- MBM can reduce the incidence of cardiac events, but not of cardiac or overall mortality.

- MBM can positively influence atherosclerosis and systolic blood pressure, but not diastolic blood pressure, LDL cholesterol, or body mass index.

- MBM programs can be considered as an adjuvant to classical rehabilitation measures in patients with $\mathrm{CHD}$. predictor for the course of CHD (e15, e16). Therefore, patients with CHD can be unreservedly recommended to take part in MBM interventions or intensified lifestyle modification programs in addition to classical cardiological rehabilitation.

\section{Acknowledgment}

This review was supported by the Rut and Klaus Bahlsen Foundation. The sponsor had no influence on the planning or execution of the review, the acquisition or interpretation of the data, or the writing of the manuscript.

\section{Conflict of interest statement}

The authors declare that no conflict of interest exists.

Manuscript received on 24 April 2015, revised version accepted on 2 July 2015

Translated from the original German by David Roseveare.

\section{REFERENCES}

1. Gößwald A, Schienkiewitz A, NowossadeckE, Busch MA: Prävalenz von Herzinfarkt und koronarer Herzkrankheit bei Erwachsenen im Alter von 40 bis 79 Jahren in Deutschland. Bundesgesundheitsbl 2013; 56: 650-5.

2. Statistisches Bundesamt: Todesursachen. www.destatis.de/DE/ ZahlenFakten/GesellschaftStaat/Gesundheit/Todesursachen/Todesursachen.html (last accessed on 16 February 2015).

3. World Health Organization: Global status report on noncommunicable diseases 2010. Geneva: World Health Organization; 2011.

4. World Health Organization: Comparative quantification of health risks: Global and regional burden of disease attributable to selected major risk factors. Geneva: World Health Organization; 2004.

5. Kassenärztliche Bundesvereinigung (KBV), Arbeitsgemeinschaft der Wissenschaftlichen Medizinischen Fachgesellschaften (AWMF): Nationale VersorgungsLeitlinie Chronische KHK - Langfassung, 3. Auflage. Version 1. www.khk.versorgungsleitlinien.de (last accessed on 16 February 2015).

6. Ornish D: Dr. Dean Ornish's program for reversing heart disease. Lewes: Ivy Books 1995

7. National Institute of Health: Mind-body medicine practices in complementary and alternative medicine. www.report.nih.gov/nihfactsheets/ viewfactsheet.aspx?csid=102 (last accessed on 1 April 2015).

8. Esch T: Selbstheilung als Teil der Medizin. Dtsch Arztebl 2014; 111: A2214-A20.

9. Dobos G, Altner N, Lange S, et al.: [Mind-body medicine as a part of German integrative medicine]. Bundesgesundheitsblatt Gesundheitsforschung Gesundheitsschutz 2006; 49: 723-8.

10. Heran BS, Chen JM, Ebrahim S, et al.: Exercise-based cardiac rehabilitation for coronary heart disease. Cochrane Database Syst Rev 2011: CD001800.

11. Ramsden CE, Zamora D, Leelarthaepin B, et al.: Use of dietary linoleic acid for secondary prevention of coronary heart disease and death: evaluation of recovered data from the Sydney Diet Heart Study and updated meta-analysis. BMJ 2013; 346: 88707.

12. Cramer H, Lauche R, Haller H, Steckhan N, Michalsen A, Dobos G: Effects of yoga on cardiovascular disease risk factors: a systematic review and meta-analysis. Int J Cardiol 2014; 173: 170-83.

13. de Waure C, Lauret GJ, Ricciardi W, et al.: Lifestyle interventions in patients with coronary heart disease: a systematic review. Am J Prev Med 2013; 45: 207-16.

14. Janssen V, De Gucht V, Dusseldorp E, Maes S: Lifestyle modification programmes for patients with coronary heart disease: a systematic review and meta-analysis of randomized controlled trials. Eur J Prev Cardiol 2013; 20: 620-40. 
15. Jhamnani S, Patel D, Heimlich L, King F, Walitt B, Lindsay J: Metaanalysis of the effects of lifestyle modifications on coronary and carotid atherosclerotic burden. Am J Cardiol 2015; 115: 268-75.

16. Moher D, Liberati A, Tetzlaff J, Altman DG: Preferred reporting items for systematic reviews and meta-analyses: the PRISMA statement. BMJ 2009; 339: b2535.

17. Higgins JPT, Green S: Cochrane handbook for systematic reviews of interventions. West Sussex: John Wiley \& Sons Ltd. 2008.

18. Bradburn MJ, Deeks JJ, Berlin JA, Russell Localio A: Much ado about nothing: a comparison of the performance of meta-analytical methods with rare events. Stat Med 2007; 26: 53-77.

19. Higgins JP, Thompson SG, Deeks JJ, Altman DG: Measuring inconsistency in meta-analyses. BMJ 2003; 327: 557-60.

20. Egger M, Davey Smith G, Schneider M, Minder C: Bias in metaanalysis detected by a simple, graphical test. BMJ 1997; 315: 629-34.

21. Albus C, Theissen P, Hellmich M, et al.: Long-term effects of a multimodal behavioral intervention on myocardial perfusion-a randomized controlled trial. Int J Behav Med 2009; 16: 219-26.

22. Aldana SG, Greenlaw R, Salberg A, Merrill RM, Hager R, Jorgensen $\mathrm{RB}$ : The effects of an intensive lifestyle modification program on carotid artery intima-media thickness: a randomized trial. Am J Health Promot 2007; 21: 510-6.

23. Gould KL, Ornish D, Scherwitz L, et al.: Changes in myocardial perfusion abnormalities by positron emission tomography after longterm, intense risk factor modification. JAMA 1995; 274: 894-901.

24. Haglin L, Lundstrom S, Kaati G, Backman L, Bygren LO: All-cause mortality of patients with dyslipidemia up to 19 years after a multidisciplinary lifestyle modification programme: a randomized trial. Eur J Cardiovasc Prev Rehabil 2011; 18: 79-85.

25. Hofman-Bang C, Lisspers J, Nordlander R, et al.: Two-year results of a controlled study of residential rehabilitation for patients treated with percutaneous transluminal coronary angioplasty. A randomized study of a multifactorial programme. Eur Heart J 1999; 20: 1465-74.

26. Lehmann N, Paul A, Moebus S, Budde T, Dobos GJ, Michalsen A: Effects of lifestyle modification on coronary artery calcium progression and prognostic factors in coronary patients-3-year results of the randomized SAFE-LIFE trial. Atherosclerosis 2011; 219: 630-6.

27. Lisspers J, Sundin 0, Hofman-Bang C, et al.: Behavioral effects of a comprehensive, multifactorial program for lifestyle change after percutaneous transluminal coronary angioplasty: a prospective, randomized controlled study. J Psychosom Res 1999; 46: 143-54.

28. Lisspers J, Sundin 0, Ohman A, Hofman-Bang C, Ryden L, Nygren A: Long-term effects of lifestyle behavior change in coronary artery disease: effects on recurrent coronary events after percutaneous coronary intervention. Health Psychol 2005; 24: 41-8.

29. Manchanda SC, Narang R, Reddy KS, et al.: Retardation of coronary atherosclerosis with yoga lifestyle intervention. J Assoc Physicians India 2000; 48: 687-94.

30. Michalsen A, Knoblauch NT, Lehmann N, et al.: Effects of lifestyle modification on the progression of coronary atherosclerosis, autonomic func- tion, and angina — the role of GNB3 C825T polymorphism. Am Heart J 2006; 151: 870-7.

31. Neves A, Alves AJ, Ribeiro F, Gomes JL, Oliveira J: The effect of cardiac rehabilitation with relaxation therapy on psychological, hemodynamic, and hospital admission outcome variables. J Cardiopulm Rehabil Prev 2009; 29: 304-9

32. Ornish D, Brown SE, Scherwitz LW, et al.: Can lifestyle changes reverse coronary heart disease? The Lifestyle Heart Trial. Lancet 1990; 336: 129-33.

33. Ornish D, Scherwitz LW, Billings JH, et al.: Intensive lifestyle changes for reversal of coronary heart disease. JAMA 1998; 280: 2001-7.

34. Pischke CR, Scherwitz L, Weidner G, Ornish D: Long-term effects of lifestyle changes on well-being and cardiac variables among coronary heart disease patients. Health psychology 2008; 27: 584-92.

35. Plüss $C E$, Billing $E$, Held $C$, et al.: Long-term effects of an expanded cardiac rehabilitation programme after myocardial infarction or coronary artery bypass surgery: a five-year follow-up of a randomized controlled study. Clin Rehabil 2011; 25: 79-87.

36. Plüss CE, Karlsson MR, Wallen N, Billing E, Held C: Effects of an expanded cardiac rehabilitation programme in patients treated for an acute myocardial infarction or a coronary artery by-pass graft operation. Clin Rehabil 2008; 22: 306-18

37. Srimahachota S, Wunsuwan R, Siritantikorn A, Boonla C, Chaiwongkarjohn S, Tosukhowong P: Effects of lifestyle modification on oxidized LDL, reactive oxygen species production and endothelial cell viability in patients with coronary artery disease. Clin Biochem 2010; 43: 858-62.

38. Toobert DJ, Glasgow RE, Nettekoven LA, Brown JE: Behavioral and psychosocial effects of intensive lifestyle management for women with coronary heart disease. Patient Educ Couns 1998; 35: 177-88.

39. Toobert DJ, Glasgow RE, Radcliffe JL: Physiologic and related behavioral outcomes from the Women's Lifestyle Heart Trial. Ann Behav Med 2000; 22: $1-9$.

40. Vestfold Heartcare Study Group: Influence on lifestyle measures and fiveyear coronary risk by a comprehensive lifestyle intervention programme in patients with coronary heart disease. Eur J Cardiovasc Prev Rehabil 2003; 10: 429-37.

\section{Corresponding author}

Dr. rer. medic. Holger Cramer

Klinik für Naturheilkunde und Integrative Medizin, Kliniken Essen-Mitte

Am Deimelsberg 34a

45276 Essen, Germany

h.cramer@kliniken-essen-mitte.de

Supplementary material:

For eReferences please refer to: www.aerzteblatt-international.de/ref4515

eTables, eFigures: www.aerzteblatt-international.de/15m0759 


\title{
Supplementary material to:
}

\section{Mind-Body Medicine in the Secondary Prevention of Coronary Heart Disease}

\author{
A Systematic Review and Meta-analysis
}

by Holger Cramer, Romy Lauche, Anna Paul, Jost Langhorst, Andreas Michalsen and Gustav Dobos

Dtsch Arztebl Int 2015; 112: 759-67. D0l: 10.3238/arztebl.2015.0759

\section{eREFERENCES}

e1. Rugulies R, Jager A, Benesch L, Siegrist J: Comprehensive lifestyle changes among patients with $\mathrm{CHD}$ and the integration of inpatient and outpatient cardiac rehabilitation: First results of a secondary prevention intervention trial. Z Gesundh Wiss 1996; 4: 234-47.

e2. Welty FK, Stuart E, O'Meara M, Huddleston J: Effect of addition of exercise to therapeutic lifestyle changes diet in enabling women and men with coronary heart disease to reach Adult Treatment Panel III low-density lipoprotein cholesterol goal without lowering high-density lipoprotein cholesterol. Am J Cardiol 2002; 89: 1201-4.

e3. Shahamfar E J, Gupta VK, Daga MK, Dastgiri S, Hakim SH, Khaki $P$ : The role of lifestyle intervention on blood pressure reduction: Its impact on coronary heart disease. J Int Med Scie Acad 2007; 20: 257-8.

e4. Yogendra J, Yogendra HJ, Ambardekar S, et al.: Beneficial effects of yoga lifestyle on reversibility of ischaemic heart disease: caring heart project of International Board of Yoga. J Assoc Physicians India 2004; 52: 283-9.

e5. Fields JZ, Walton KG, Schneider RH, et al.: Effect of a multimodality natural medicine program on carotid atherosclerosis in older subjects: a pilot trial of Maharishi Vedic Medicine. Am J Cardiol 2002; 89: 952-8.

e6. Lovibond SH, Birrell PC, Langeluddecke P: Changing coronary heart disease risk-factor status: the effects of three behavioral programs. J Behav Med 1986; 9: 415-37.

e7. Castaldo JE, Reed lii JF: The lowering of vascular atherosclerotic risk (LOVAR) program: An approach to modifying cerebral, cardiac and peripheral vascular disease. J Stroke Cerebrovasc Dis 2008; 17: 9-15

e8. Singh RB, Singh NK, Rastogi SS, Mani UV, Niaz MA: Effects of diet and lifestyle changes on atherosclerotic risk factors after 24 weeks on the Indian diet heart study. Am J Cardiol 1993; 71: $1283-8$.

e9. Goodman H, Parsons A, Davison J, et al.: A randomised controlled trial to evaluate a nurse-led programme of support and lifestyle management for patients awaiting cardiac surgery. 'Fit for surgery: Fit for life' study. Eur J Cardiovasc Nurs 2008; 7: 189-95.

e10. Wallner $\mathrm{S}$, Watzinger $\mathrm{N}$, Lindschinger $\mathrm{M}$, et al.: Effects of intensified lifestyle modification on the need for further revascularization after coronary angioplasty. Eur J Clin Invest 1999; 29: 372-9.

e11. Brugemann J, Poels BJ, Oosterwijk MH, van der Schans CP, Postema $\mathrm{K}$, van Veldhuisen DJ: A randomised controlled trial of cardiac rehabilitation after revascularisation. Int J Cardiol 2007; 119: 59-64.

e12. Sundin O, Lisspers J, Hofman-Bang C, Nygren A, Rydén L, Ohman $A$ : Comparing multifactorial lifestyle interventions and stress management in coronary risk reduction. Int J Behav Med 2003; 10 : 191-204.

e13. Jatuporn S, Sangwatanaroj S, Saengsiri A0, et al.: Short-term effects of an intensive lifestyle modification program on lipid peroxidation and antioxidant systems in patients with coronary artery disease. Clin Hemorheol Microcirc 2003; 29: 429-36.

e14. Gartlehner G: Assessment of adverse effects and applicability — two areas not (yet) covered adequately in Cochrane reports. Z Evid Fortbild Qual Gesundhwes 2008; 102: 497-502.

e15. Nakatani D, Sakata Y, Suna S, et al.: Incidence, predictors, and subsequent mortality risk of recurrent myocardial infarction in patients following discharge for acute myocardial infarction. Circ $\mathrm{J}$ 2013; 77: 439-46

e16. Thune JJ, Signorovitch JE, Kober L, et al.: Predictors and prognostic impact of recurrent myocardial infarction in patients with left ventricular dysfunction, heart failure, or both following a first myocardial infarction. Eur J Heart Fail 2011; 13: 148-53. 


\section{Search strategy}

\section{PubMed}

\#1 "Lifestyle Modification “[Title/Abstract] OR "Mind-Body Therapies"[Mesh] OR „Mind-Body"[Title/Abstract] OR „Mind/Body”[Title/Abstract] OR „Ornish” [Title/Abstract]

\#2 "Diet"[Mesh] OR "Diet"[Title/Abstract] OR "Food"[Mesh] OR "Food"[Title/Abstract] OR "Nutrition Therapy"[Mesh] OR "Nutrition"[Title/Abstract] OR "Mediterranean"[Title/Abstract]

\#3 "Exercise"[Mesh] OR "Exercise Therapy"[Mesh] OR "Exercise"[Title/Abstract] OR "Physical Activity"[Title/Abstract] OR "Sports"[Mesh] OR "Sports" [Title/Abstract] "Running"[Mesh] OR "Running"[Title/Abstract] "Walking"[Mesh] OR "Walking"[Title/Abstract] "Swimming"[Mesh] OR "Swimming"[Title/ Abstract] OR "Jogging"[Title/Abstract] OR "Cycling"[Title/Abstract] OR "Aerobics"[Title/Abstract]

\#4 "Stress Management"[Title/Abstract] OR "Stress Reduction"[Title/Abstract] OR "Relaxation"[Mesh] OR "Relaxation Therapy"[Mesh] OR "Relaxation"[Title/Abstract] OR "Yoga"[Mesh] OR "Yoga"[Title/Abstract] OR "Meditation"[Mesh] OR "Meditation"[Title/Abstract] OR "Mindfulness" [Mesh] OR "Mindfulness"[Title/Abstract] OR "Imagery (Psychotherapy)" [Mesh] OR "Imagery"[Title/Abstract] OR "Biofeedback, Psychology"[Mesh] OR "Biofeedback"[Title/Abstract]

\#5 \#2 AND \#3 AND \#4

\#6 $\quad$ \#1 OR \#5

\#7 "Coronary Artery Disease"[Mesh] OR "Coronary Artery"[Title/Abstract] OR "Coronary Heart"[Title/Abstract] OR "Atherosclerosis"[Mesh] OR "Atherosclerosis"[Title/Abstract] OR "Arteriosclerosis"[Title/Abstract]

\#8 "Randomized Controlled Trial"[Publication Type] OR "Controlled Clinical Trial"[Publication Type] OR "Randomized"[Title/Abstract] OR "Placebo"[Title/ Abstract] OR "Random"[Title/Abstract] OR "Randomly"[Title/Abstract] OR "Trial"[Title/Abstract] OR "Group"[Title/Abstract]

\#9 "Animals"[Mesh] NOT "Humans"[Mesh]

\#10 \#6 AND \#7 AND \#8 NOT \#9

Cochrane Library

\#1 "Lifestyle Modification“ or "Mind-Body“ or "Mind/Body” OR "Ornish”:ti,ab,kw (Word variations have been searched)

\#2 MeSH descriptor: [Mind-Body Therapies] explode all trees

\#3 \#1 OR \#2

\#4 "Diet" or „Food" or „Nutrition“ or "Mediterranean“.ti,ab,kw (Word variations have been searched)

\#5 MeSH descriptor: [Diet] explode all trees

\#6 $\quad$ MeSH descriptor: [Food] explode all trees

\#7 MeSH descriptor: [Nutrition Therapy] explode all trees

\#8 \#4 OR \#5 OR \#6 OR \#7

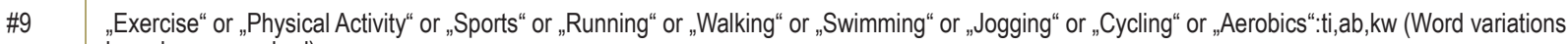
have been searched)

\#10 MeSH descriptor: [Exercise] explode all trees

\#11 MeSH descriptor: [Exercise Therapy] explode all trees

\#12 MeSH descriptor: [Sports] explode all trees

\#13 MeSH descriptor: [Running] explode all trees

\#14 MeSH descriptor: [Walking] explode all trees

\#15 MeSH descriptor: [Swimming] explode all trees

\#16 \#9 OR \#10 OR\#11 OR\#12 OR \#13 OR\#14 OR \#15

\#17 "Stress Management" or „Stress Reduction“ or „Relaxation" or „Yoga“ or „Meditation“ or "Mindfulness" or „Imagery“ or „Biofeedback“.ti,ab,kw (Word variations have been searched)

\#18 MeSH descriptor: [Relaxation] explode all trees

\#19 MeSH descriptor: [Relaxation Therapy] explode all trees

\#20 MeSH descriptor: [Yoga] explode all trees

\#21 MeSH descriptor: [Meditation] explode all trees

\#22 MeSH descriptor: [Mindfulness] explode all trees

\#23 MeSH descriptor: [Imagery (Psychotherapy)] explode all trees

\#24 MeSH descriptor: [Biofeedback, Psychology] explode all trees

\#25 \#17 OR \#18 OR \#19 OR \#20 OR \#21 OR \#22 OR \#23 OR \#24

\#26 \#8 AND \#16 AND \#25 


\begin{tabular}{|c|c|}
\hline \#27 & \#3 OR \#26 \\
\hline \#28 & "Coronary Artery" or „Coronary Heart" or „Atherosclerosis“ or „Arteriosclerosis“:ti,ab,kw (Word variations have been searched) \\
\hline \#29 & MeSH descriptor: [Coronary Artery Disease] explode all trees \\
\hline$\# 30$ & MeSH descriptor: [Atherosclerosis] explode all trees \\
\hline \#31 & \#28 OR \#29 OR \#30 \\
\hline \#32 & \#27 AND \#31 \\
\hline \multicolumn{2}{|c|}{ Scopus } \\
\hline$\# 1$ & TITLE-ABS-KEY ( „Lifestyle Modification“ OR „Mind-Body“ OR „Mind/Body“ OR „Ornish“ ) \\
\hline \#2 & TITLE-ABS-KEY ( „Diet“ OR „Food“ OR „Nutrition“ OR „Mediterranean“ ) \\
\hline \#3 & $\begin{array}{l}\text { TITLE-ABS-KEY ( „Exercise“ OR „Physical Activity“ OR „Sports“ OR „Running“ OR „Walking“ OR „Swimming“ OR „Jogging“ OR „Cycling“ OR } \\
\text { „Aerobics“) }\end{array}$ \\
\hline \#4 & $\begin{array}{l}\text { TITLE-ABS-KEY ( „Stress Management" OR „Stress Reduction“ OR „Relaxation“ OR „Yoga“ OR „Meditation“ OR „Mindfulness“ OR „Imagery“ } \\
\text { OR „Biofeedback“) }\end{array}$ \\
\hline \#5 & \#2 AND \#3 AND \#4 \\
\hline \#6 & \#1 OR \#5 \\
\hline \#7 & TITLE-ABS-KEY ( „Coronary Artery“ OR „Coronary Heart" OR „Atherosclerosis“ OR „Arteriosclerosis“ ) \\
\hline \#8 & TITLE-ABS-KEY ( „Randomized“ OR „Randomised“ OR „Placebo“ OR „Random“ OR „Randomly“ OR „Trial“ OR „Group“ ) \\
\hline$\# 9$ & \#6 AND \#7 AND \#8 \\
\hline
\end{tabular}




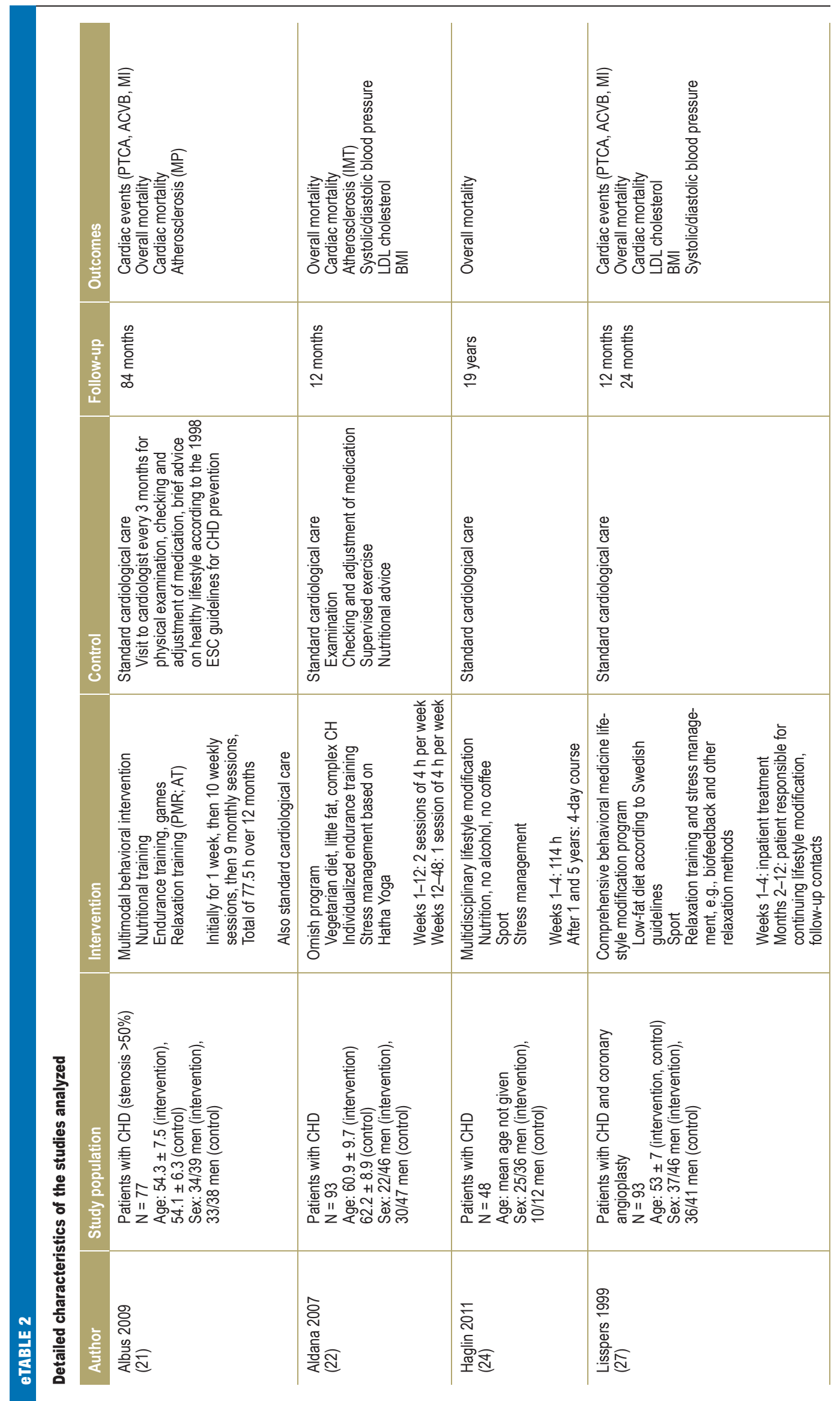




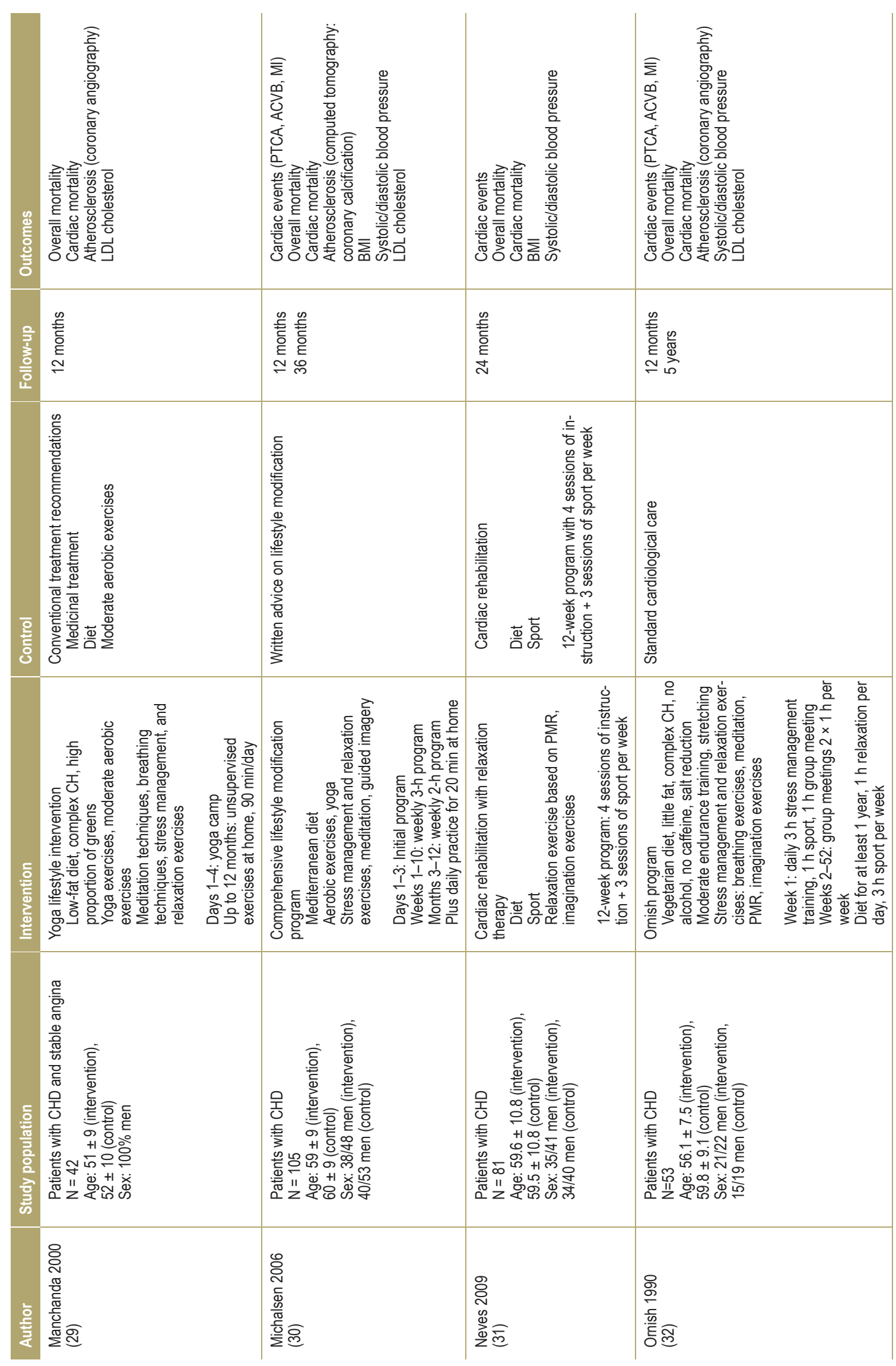




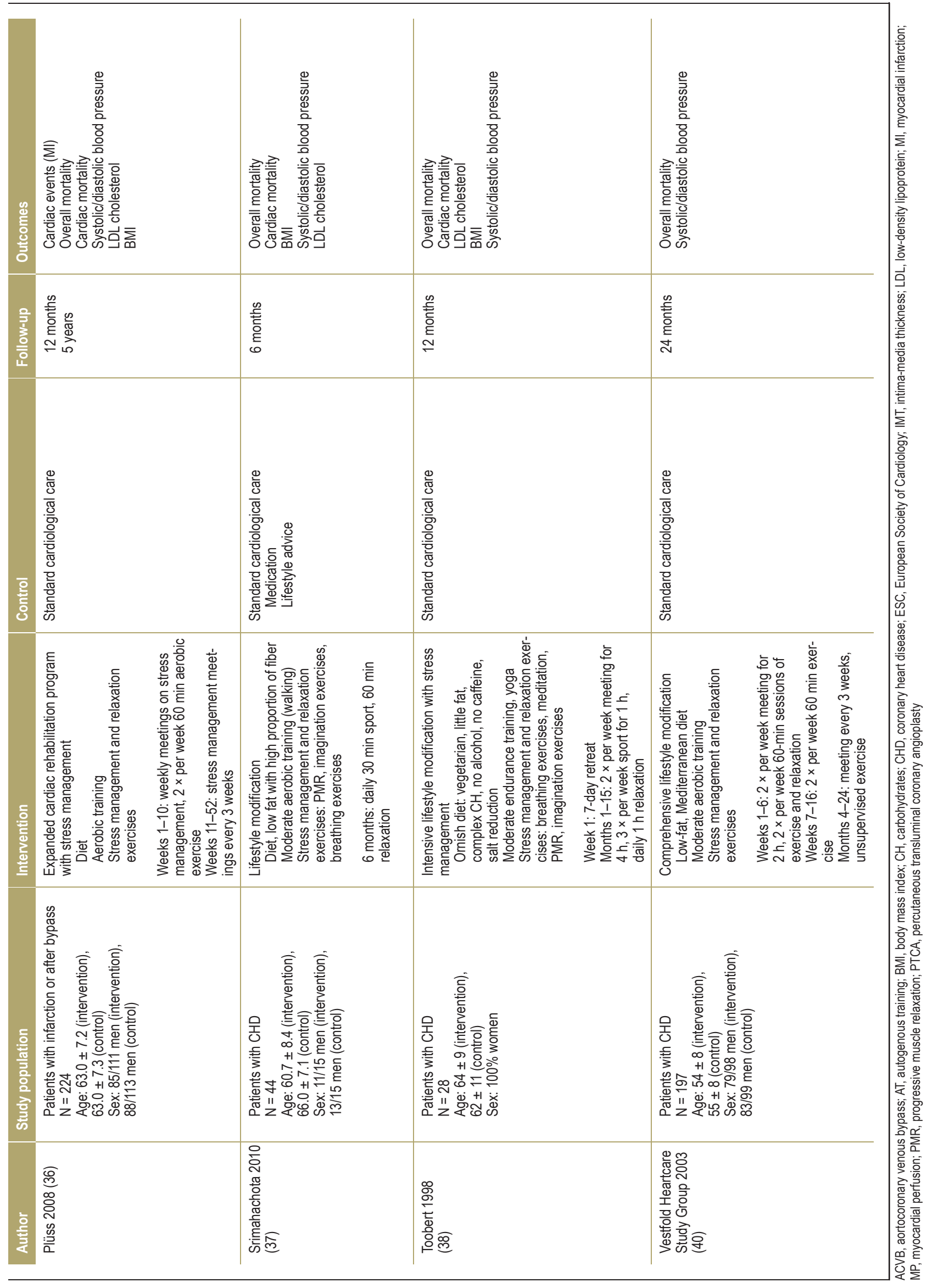




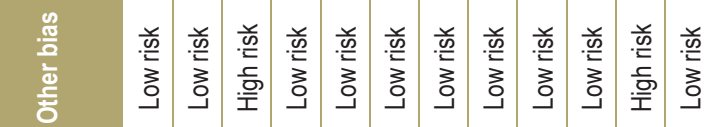

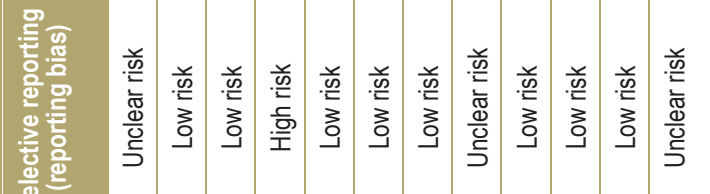

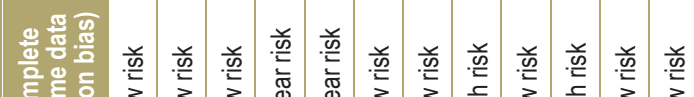

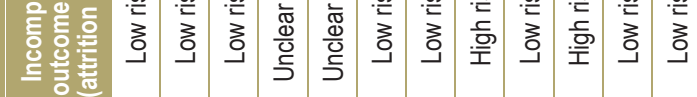

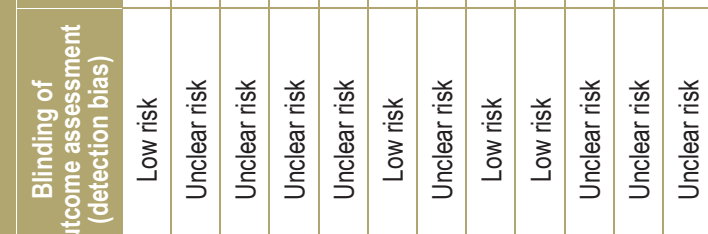

$\frac{9}{m}$

○े

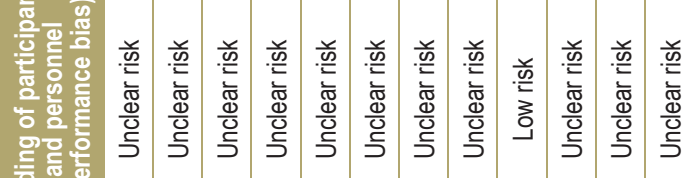

衰

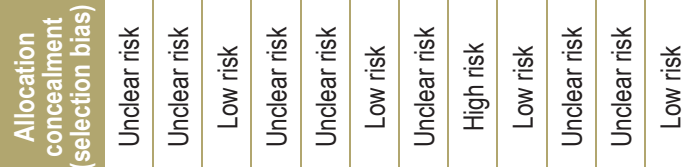

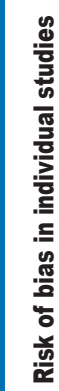

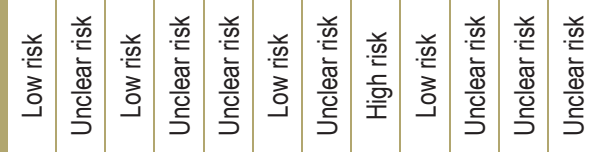

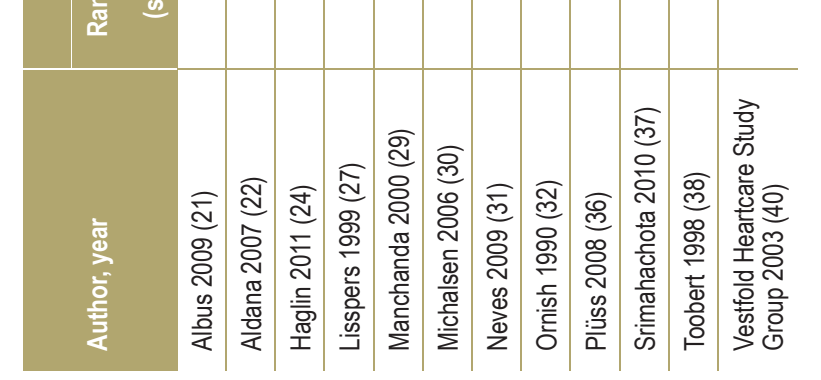




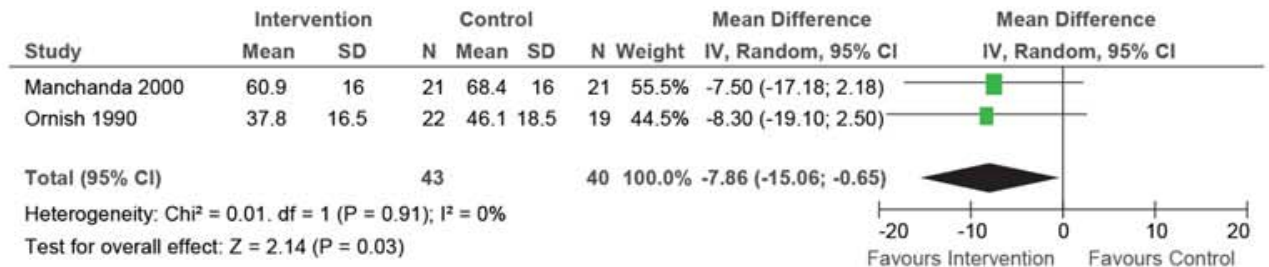

A

\begin{tabular}{|c|c|c|c|c|c|c|c|c|c|c|}
\hline \multirow[b]{2}{*}{ Study } & \multicolumn{3}{|c|}{ Intervention } & \multicolumn{2}{|c|}{ Control } & \multirow[b]{2}{*}{$\mathrm{N}$} & \multirow[b]{2}{*}{ Weight } & \multirow{2}{*}{$\begin{array}{c}\text { Mean Difference } \\
\text { IV, Random, } 95 \% \mathrm{CI}\end{array}$} & \multirow{2}{*}{\multicolumn{2}{|c|}{$\begin{array}{l}\text { Mean Difference } \\
\text { IV, Random, } 95 \% \mathrm{CI}\end{array}$}} \\
\hline & Mean & SD & $\mathrm{N}$ & Mean & SD & & & & & \\
\hline Aldana 2007 & 127.37 & 14.83 & 46 & 126.72 & 20.12 & 47 & $11.4 \%$ & $0.67(-6.50 ; 7.84)$ & & \\
\hline Michalsen 2006 & 125.4 & 13.8 & 48 & 128.3 & 14.1 & 53 & $19.8 \%$ & $-2.90(-8.35 ; 2.55)$ & & \\
\hline Neves 2009 & 119.9 & 6.6 & 40 & 126.5 & 15 & 40 & $22.8 \%$ & $-6.60(-11.68 ;-1.52)$ & $\rightarrow$ & \\
\hline Ornish 1990 & 127 & 13 & 22 & 131 & 20 & 19 & $5.3 \%$ & $-4.00(-14.51 ; 6.51)$ & & \\
\hline Pluss 2008 & 139 & 23 & 111 & 142 & 24 & 113 & $15.5 \%$ & $-3.00(-9.16 ; 3.16)$ & & \\
\hline Srimahachota 2010 & 128.29 & 8.41 & 15 & 134.62 & 20.76 & 15 & $4.6 \%$ & $-6.31(-17.65 ; 5.03)$ & & \\
\hline Toobert 1998 & 135 & 22 & 14 & 147 & 28 & 11 & $1.4 \%$ & $-12.00(-32.16 ; 8.16)$ & & \\
\hline Vestfold 2003 & 130 & 17 & 79 & 131 & 19 & 83 & $19.1 \%$ & $-1.00(-6.55 ; 4.55)$ & & \\
\hline Total $(95 \% \mathrm{Cl})$ & & & 375 & & & 381 & $100.0 \%$ & $-3.33(-5.76 ;-0.91)$ & & \\
\hline \multicolumn{6}{|c|}{ Heterogeneity: $\mathrm{Chi}^{2}=4.49 . \mathrm{df}=7(\mathrm{P}=0.72) ; \mathrm{I}^{2}=0 \%$} & & & & -20 & 10 \\
\hline
\end{tabular}

B Test for overall effect: $Z=2.70(P=0.007$

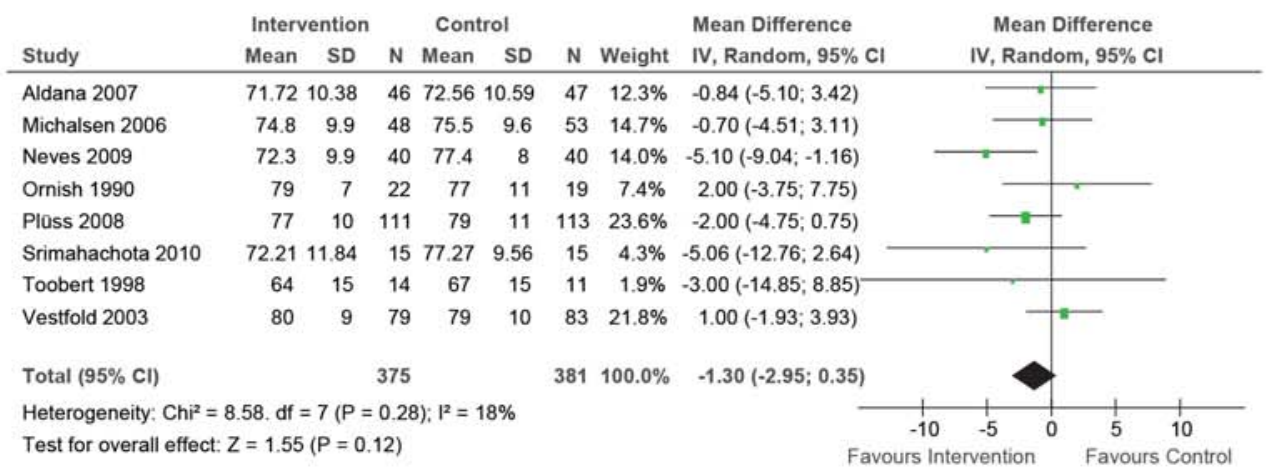

C Test for overall effect: $Z=1.55(P=0.12)$
Meta-analyses of secondary outocmes:

A) atherosclerosis;

B) systolic blood pressure;

C) diastolic blood pressure;

D) LDL cholesterol;

E) body mass index.

IV, inverse variance;

$\mathrm{Cl}$, confidence interval; SD, standard deviation

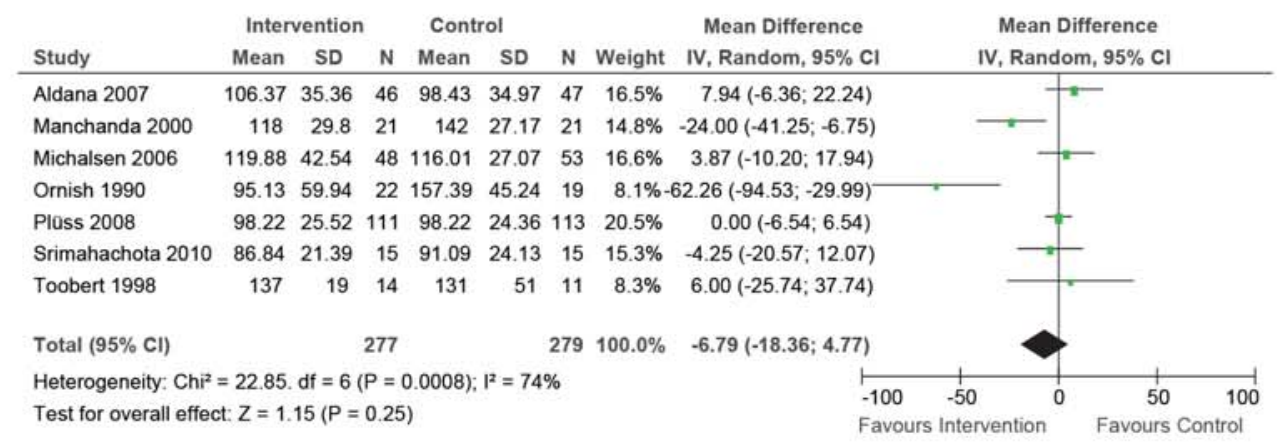

D Test for overall effect: $Z=1.15(P=0.25)$

Favours Intervention Favours Control

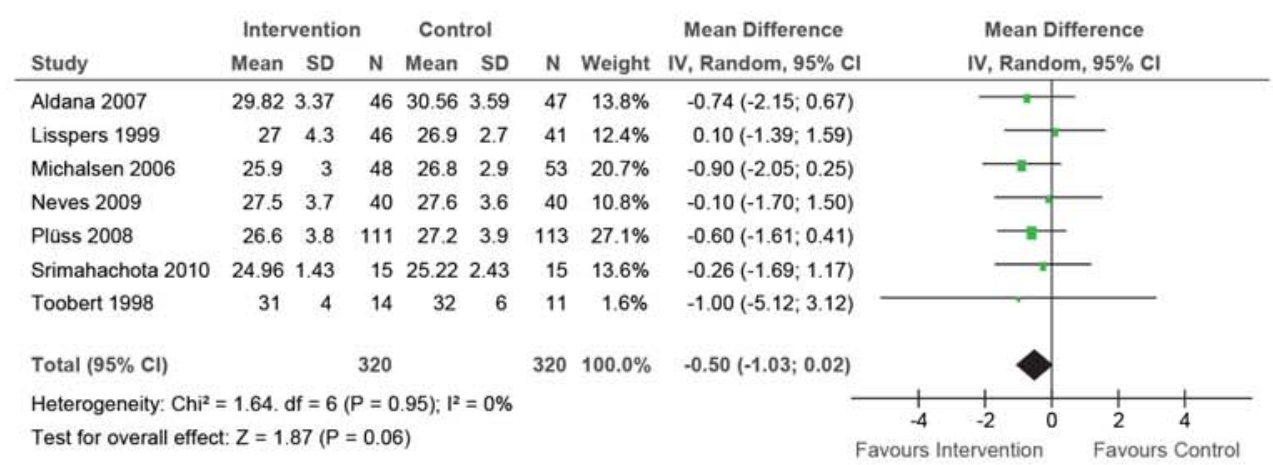




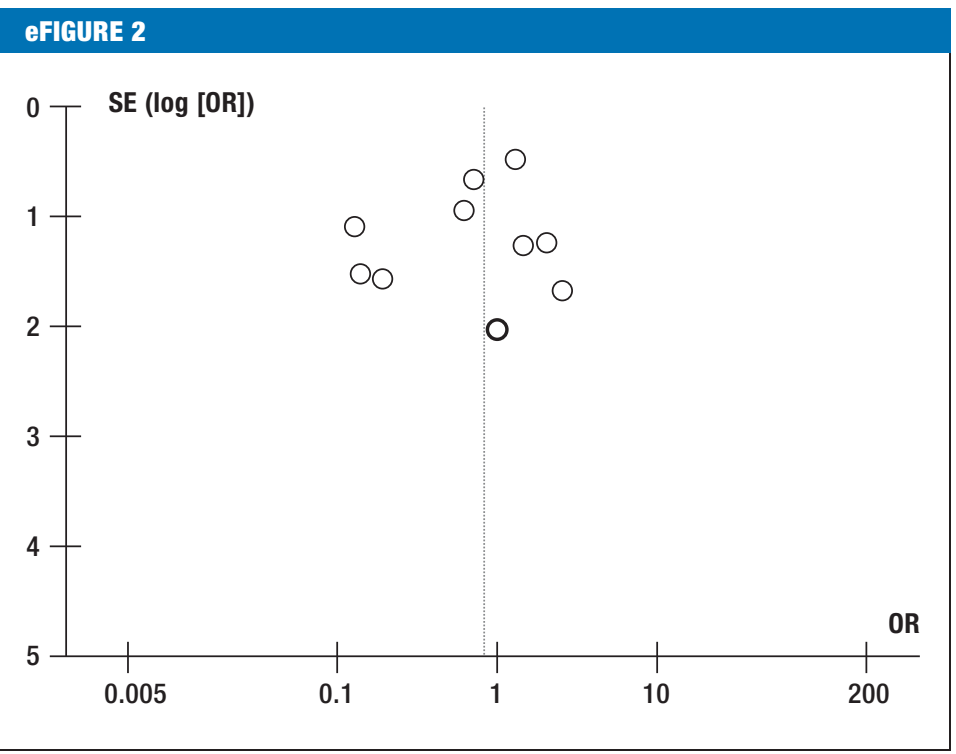

Funnel plot for meta-analysis of overall mortality.

$\mathrm{OR}$, odds ratio; $\mathrm{SE}$, standard error

\section{eFIGURE 3}

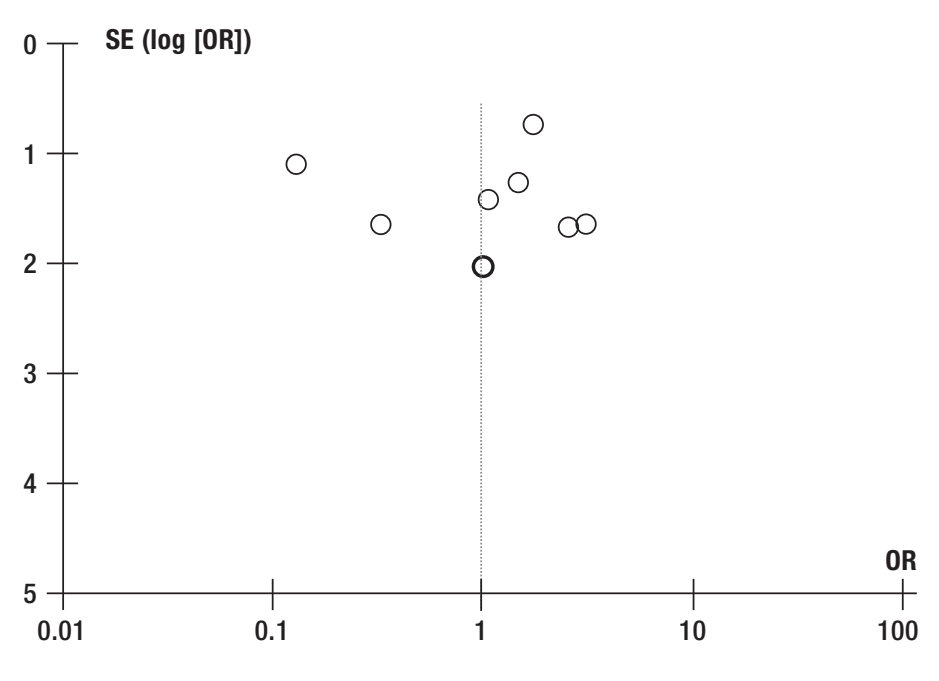

Funnel plot for meta-analysis of cardiac mortality.

$\mathrm{OR}$, odds ratio; $\mathrm{SE}$, standard error 